\title{
İSLAM MÜELLİFLERINNE GÖRE ORTAÇAĞ'DA OŞ ŞEHRI
}

\section{GÜLNISA AYNAKULOVA*}

Fergana vadisi Orta Asya'nın en eski yerleşim merkezlerindendir ve doğal olarak Orta Asya'nın en köklü şehirlerinden bazıları da bu bölgede yer almışur. Yıllardır yapılan arkeolojik kazıların sonuçları bölgede tarımla uğraşanların ilk yerleşme yerlerinin üç bin yl önce meydana geldiğini ortaya koymuştur ${ }^{1}$ ve bu eski meskun yerlerden biri de günümüzde üç bininci yldönümünü kutlamakta olduğumuz eski $\mathrm{O}$ ş şehrinin en eski çekirdeğini teşkil etmiştir².

Oş şehrinin yazılı tarihi bin yıl öncesine kadar gitmektedir. Önce Saka, Wusun, Hun hakimiyetler; ${ }^{3}$ ve sonraları Göktürk, Karahanlı kağanlıklarının sınırları içinde bulunan $\mathrm{O}$ şehrinin ortaçağ dönemi, yalnızca şehrin değil, bütün Orta Asya ülkelerinin sonraki tarihi, kültürü ve dini üzerinde derin iz bırakan önemli dıs siyaset olaylarına bağlıdır. Onlardan biri bölgenin Araplar tarafindan fethedilmesidir.

İlk zamanlarda şehirlerin bayındırlığına büyük zarar veren Arap fetihleri aynı zamanda onların görünüşlerinin tamamıyla değişmesinde de büyük rol oynamıștır. Orta Asya'nın Arap Hilafetine bağlanması Yakın Doğu ile Maveraünnehir arasındaki ticari ilişkilerin genişlemesine yol açmış ve bu durum doğal olarak şehirlerin gelişmesinde de büyük etken olmuştur ${ }^{4}$. Bölgenin İslam sancağı altuna girmesi dolayısıyla bir merkezden yönetilen muntazam Hilafet Devleti kuruluş sistemine bağlanması kültürel ilişkilerin ilerlemesine, ticaretin ve zanaatun gelişmesine yol açarak, Orta Asya'nın IX$\mathrm{X}$. yüzyıllarda meydana gelen ikinci şehirleşme döneminde önemli rol oynamıştır ${ }^{5}$. İslam müelliflerinin Maveraünnehir şehirleri hakkında yazdıkları ile yapılan arkeolojik araşturmalar sonucu elde edilen bilgiler, bu

- Gazi Üniversitesi, Tarih Bōlūmü Öğretim Görevlisi.

${ }^{1}$ Zadneprovskiy Yu. A., s. 56, 58-59.

2 Bu sehrin adının Us șeklinde okunması daha uygundur. Zira kaynaklarda Uç sekli de geçer. Sınır demektir. [Bkz. İslam Coğrafyacılarına göre Türkler, s. 29, 65, 96 vd].

${ }^{3}$ Bernștam A.N., s. 17.

${ }^{4}$ Gafurov B.G., s. 182.

${ }^{5}$ Belenitskiy A.M., s. 162. 
tarihi döneme özgü vasıfların ve olaylann $\mathrm{O}$ şehri dahil olmak üzere bütün Fergana sehirlerinin kaderinde de belli bir derecede iz bıraktıklarını göstermektedir. Os şehri $\mathrm{X}$. yüzyıl sonlarına kadar İslam dünyasının doğusundaki Kafir Türklere karşı bir Uç (sınır) şehriydi. Belki de adını buradan almıştr. Bu sebeple bazı kaynaklarda Uç şeklinde okunur.

IX-X yüzylların Fergana bölgesi İslam coğrafyacıları tarafindan detaylı bir şekilde tasvir edilmiştir. Söz konusu dönemde O\$ şehri ekonomik açıdan bağımsız durumda olan güney Fergana'nın Nesya bölgesinin hudutlanı içinde idi ${ }^{6}$. Şehir Bat ülkeleri ile Şark dünyasını bağlayan Büyük İpek Yolu üzerindeki eski ticaret yolunun bir kolunda yer almaktaydi. Eski Arap coğrafyacılarından İbn Hurdadbih bu yolu şöyle tasvir eder: "Batı Asya'dan Hilafetin şark hududuna giden ana yol Hocent'te Sirderya'yı aşar, ondan sonra Ahsiket'e kadar sağ sahili takip eder ve Ahsiket'ten sonra yeniden nehri aşarak Kuba, Oş ve Uzkend'e (Özkent-Özgön-G.A.) ulaşır'? El-İ̀stahrî Sirderya'nın güneyindeki mıntukalardan geçen bu yolu ana yol sayıyordu ${ }^{8}$. Bu ana yol üzerinde Kend, Soh, Riştan, Zenderamiş, Kuba, Oş ve Uzkend şehirleri bulunuyordu.

Söz konusu dönemde Oş, Fergana vilayetinin başkenti Ahsiket ve Kuba'dan sonraki üçüncü büyük şehirdi. Oş hakkında ilk bilgiyi Abu'l-Kasım İbn Hurdadbih verir. Onun Memaliku'l-Mesalik'inde O§̧ şehrinden Özkend'e kadar yedi fersah veya bir büyük mesafe olduğu söylenir'. Mukaddesî'ye göre Oş, neirleri bol, çeşitli özelliklere sahip bir şehirdir. Ferah ve bolluktur. Dağa yakın zengin bir yer olup, suları boldur ${ }^{10}$. Sehrin sehristanı ve kuhendizi (kalesi) bayındır olup, Darü'l-İmâre ve hapishane kuhendizin içindeydi. Sehristanda rıbat vardı. Rubat dağa kadar uzanan duvarla çevriliydi. Bu dağ üzerinde (kafir) Türklere gözetleme yapan karakol bulunurdu ${ }^{11}$. Karakola her taraftan gönüllüler gelirdi ${ }^{12}$. Şehrin üç kapısı vardı: Dervaze-î Kuh (Dağ kapısı), Dervaze-î Āb (Su kapısı) ve Dervaza-î Muğkede (Muğkede kapısı). Bu kapılar müstahkemdi ${ }^{13}$. Muğkede "ateşe tapanlar mabedi kapısı"

\footnotetext{
${ }^{6}$ Bernstam A.N., s. 30.

${ }^{7}$ Ibn Hurdadbih, s. 30.

${ }^{8}$ Istahri, s. 335.

9 Ibn Hurdadbih, s. 65.

${ }^{10}$ Mukaddesi, s. 272; İslam Coğrafyacılanna göre Türkler, s. 250.

11 istahri, s. 335.

12 Mukaddesi, s. 272.

13 tbn Havkal, s. 513; Islam Coğrafyacılanna göre Türkler, s. 240.
} 
anlamına gelip, eski Zerdüştlük dininin bir yankısıydı. Bu yüzyıllarda $\mathrm{O}$ s sakinlerinin ancak küçük bir kısmı Zerdüştlük mezhebi mensupları olduğu anlaşılmaktadır. Çünkü X. yüzyılda İslamiyetin Fergana'nın bütün ahalisinin hâkim dini durumuna geldiği bilinmektedir ${ }^{14}$.

Oş'un etrafındaki tarımla uğraşan meskun yerler (Özkend ve Kuba'nın etrafında olduğu gibi) şehir için birer dış istihkam hattı görevini yapmaktaydı. Bunun dışında Oş'un güneydoğusunda 2 fersahlık ${ }^{15}$ mesafede zamanına göre mükemmel bir kaleye sahip olan Medva şehri vard. ${ }^{16}$. Oş'tan farklı olarak Kuba ve Özkend'in etrafinda șehirler yoktu.

Hududü'l-Âlem'de Oş, kalabalık ve zengin bir şehir olarak gösterilir. Halkı çok savaşçıydı. Şehir dağın eteğinde yer alıp, dağın üzerinde gözetleme karakolları çoktu ${ }^{17}$. Oş hakkındaki bilgilere, büyük Türk alimi dilbilimci Kaşgarlı Mahmud'un ünlü Divanü Lügati't-Türk'ünde de rastlanır. Kaşgarlı Oş için 'tanınmış bir şehir' adı demekle birlikte, şehir adının $U c$ diye diğer bir yazılışını da verir ${ }^{18}$.

Ve nihayet Arap dünyasının son "klasik" coğrafyacılardan Yakut elHamav̂, Mu'cemü'l-Büldan adlı ansiklopedik sözlüğünde Oş'un büyük bir şehir olduğunu, duvarlarla çevrili olup, dört kapısı bulunduğunu söyler. Daha önceki coğrafyacılar şehrin ancak üç kapısından söz etmişse de arada geçen 2-3 yüzyll boyunca şehrin daha da büyüdüğü, daha müreffeh olduğu anlaşılmaktadır.Süleyman Dağı'nın üzerinde hala göçebe Türklere karşı karakol bulunuyordu. Ona göre Oş, Kuba'nın yakınında yer alıp, şehir ve civarındaki topraklar çok bereketliydi ${ }^{19}$.

Yazılı belgeler ortaçağ Os şehri üzerine yapılan arkeolojik buluntular tarafindan da doğrulanmaktadır. Günümüzde şehrin çeşitli semtlerinde elde edilmekte olan seramik su boruları, şehrin yüksek kültür seviyesini açıkça ortaya koymaktadır. Ortaçağda Oş şehrinin ayrıntılı șehir planı bilinmemektedir. Fakat bilindiği gibi, bu ve sonraki dönem Doğu ülkelerinde ana caddeler genelde iç şehri çevreleyen duvar kapısından diğer duvar kapılarına kadar giderdi. Sehir mahallelerinin içinde kerpiçten

\footnotetext{
${ }^{14}$ Galitskiy V. Ya., s. 24.

15 Istahri, s. 347.

${ }^{16}$ Ibn Havkal, s. 514.

${ }^{17}$ Hudûd, (f. 226).

${ }^{18}$ Besim Atalay, I., s. 35.

${ }^{19}$ Yakut, I., s. 374-375.
} 
yapılmış duvarların ötesinde asilzadelerin, arazi sahiplerinin, büyük tüccar sınıfının evleri, avlu yapıları yer alırdı. Burada şehristan hudutları içinde çoğu zaman şehir kapılarına yakın yerlerde yapılan kalabalık, gürültülü çarşılar içindeki yüksek minareli Cuma camisi diğer yapılardan oldukça fark gösterirdi. Şehrin muhtelif yerlerinde mahalli camiler ve medreseler bulunuyordu ${ }^{20}$.

IX-XII. yüzyllarda diğer Fergana şehirlerinde olduğu gibi Oş'un da zanaat ve ticaret merkezi rıbatlardı. Şehir zanaatunda çömlekçilik baş rolü oynamaktaydı. Fakat bunun dışında arkeolojik belgelere ve yazılı kaynaklara göre inşaat sanatının, demirciliğin çeşitli türleri çok gelişmişti. Oş çömlekçilerinin eşyaları diğer Orta Asya çömlekçilerininki gibi, her türlü işte kullanılmak üzere yapılmış çeşitlerinin bolluğu ve şekil çeşitliliğiyle farklar göstermekteydi. Bunlar hububat, su, şarap ve benzeri şeyler saklamak için üretilen büyük hacimli kaplardan başlayıp kokulu yağlar ve civa saklamak için üretilmiş küçük ölçülü kaplara kadar varan eşyalardı. Aynı zamanda çeşitli motifler, renkli desenlerle süslenmiş, mineyle kaplanmış çini eşyalar da bol çeşitlere sahipti... ${ }^{21}$ Ribatlarda şehrin zanaat-ticaretle uğraşan ahalisi ile göçebe Türkler arasında mal mübadelesi yapılırdı.

Fergana şehirlerinin Doğu Türkistan ile olan ticari bağlantuları ve uluslar arası ticarî ilişkileri de (Oş'un yer aldığı) bu Eski İpek Yolu üzerinde yapılırdı. Bu yol Akdeniz ile Uzak Doğu'yu birleştirirdi. IX-X. yüzyıl Arap coğrafyacılarının verdikleri bilgiler, söz konusu dönemde Fergana üzerinden geçen Büyük Ticaret Yolu'nun bir "kısmını" ve onun kollarını bir dereceye kadar gözlerimizin önüne koyma imkanı vermektedir. Yolun bu "kısmın" ana kolu Abbasi hilafetinin başkenti Bağdat'tan başlıyordu. Bağdat, bütün İslam dünyasının en önemli ve en büyük kültür ve ticaret merkezi olup dünyanın bir çok ülkesi ile münasebette bulunmaktayd.

Bağdat'tan Orta Asya'ya yol Merv üzerinden geçerdi. Merv șehrinden Amul şehrine (şimdiki Çarcou) ulaşırdı. İbn Hurdadbih ve İbnü'l-Fakih'in verdiği bilgilere göre, bu şehirler arasındaki mesafe 36 fersah idi ${ }^{22}$.

Ticaret yolu Amul'dan Buhara'ya geçerdi. Amul'dan Buhara'ya kadar olan mesafe İbn Hurdadbih'e göre 19, İbnü'l-Fakih'e göre 17 fersah idi ${ }^{23}$.

\footnotetext{
${ }^{20}$ Galitskiy, s. 19.

${ }^{21}$ Galitskiy, s. 21.

22 Ibn Hurdadbih, s. 25, İbnül-Fakih, s. 325.

23 Ibn Hurdadbih, s. 25, İbnül-Fakih, s. 325.
} 
Ticaret yolu Buhara'dan Semerkant'a ulaşırdı. Buhara-Semerkant arası İbn Hurdadbih'e göre 39, İbnü'l-Fakih'e göre 37 fersahtrr $^{24}$. Sonra yol Zamin şehrine ulaşırdı. İbn Hurdadbih ve İbnü'l-Fakih'e göre, Semerkant ve Zamin arasındaki mesafe 17 fersahtr ${ }^{25}$.

Zamin şehrinde Büyük Ticaret Yolu Güney (Fergana) kolu ve Kuzey (Şaş-Türk) kolu olmak üzere ikiye ayrılırdı. Güney kolunu bütünüyle alırsak, Fergana üzerinden, yukarıda söz ettğimiz Hocend, Kend, Soh, Riştan, Zenderamş, Kuba, Oşve Uzkend şehirleri üzerinden, Doğu Tanrı Dağları'na varırdı. Zamin'den çıkan yol Hocend üzerinden, Fergana'nın o zamanki başkenti Ahsiket'e de giderdi. Zamin ile Ahsiket arası İbn Hurdadbih ve İbnül-Fakih'e göre 33 fersah idi ${ }^{26}$. Fergana Ticaret Yolu vadinin güneyindeki ve kuzeyindeki dağ etekleri üzerinden geçerdi ve Oş'a gelince iki kola ayrılırdı. Onlardan biri Oş'a sonra Medva şehri ve sonra Alay Dağları üzerinden Doğu Türkistan'a ulaşırdı. İkinci yol ise Oş'tan Özkend'e gider, sonra Merkezî Tanrı Dağları boğazları üzerinden Isık-Göl'ün güneydoğu sahillerine varırdı ve oradan da Doğu Türkistan'a ve Çin'in iç bölgelerine ulaşırdı.

Fergana zanaatçılarının maharetle yaptığı çeşitli mallar da bu OşÖzkend - Doğu Türkistan güzergahı üzerinden şark ülkelerine ihraç edilirdi. Kervan ticareti esas olarak Doğu ve Batı arasında nadir rastlanan malların mübadelesini yapardı. Transit ticaret malları genelde lüks eşyalar idi. Değerli taşlar, inci, altun, gümüş ve bunlardan yapılmış eşyalar, kürkler, hahılar, ipek kumaşlar, baharatlar, ilaçlar, cins atlar, nadir güzellikte porselenler. Bu yükün büyük kısmını ipek teşkil ederdi. Söz konusu dönemlerde Orta Asya kervan ticaretinde baş rolü Semerkant, Beykent, Merv, Fir, Taraz ve Suyab oynamaktaydı.

Ülkenin ekonomik açıdan gelişmesiyle birlikte şehirlerin göçebelerle olan ticari ilişkileri de genişliyordu. Vâha ve şehir halkı hayvanlar, hayvancılık ve avcılık mamulleri, köleler, keçe alırlardı. Bunun karşılı̆̆ı olarak göçebeler kumaş, ekmek, kapkacak, demir eşyaları, süs eşyaları alırlardı. Oş şehrinin coğrafi, ekonomik ve ticari açıdan çok elverişli, stratejik bölgede yer alması onun ortaçağdaki bir ticaret merkezi ve transit noktası olarak ne derecede önem taşıdığını açık bir şekilde ortaya koymaktadır. Orta

${ }^{24}$ İbn Hurdadbih, s. 26, İbnūl-Fakih, s. 325.

${ }^{25}$ İbn hurdadbih, s. 27.

${ }^{26}$ İbn hurdadbih, s. 30, İbnül-Fakih, s. 328. 
Asya'da IX-X. yüzyllarda üretimin oldukça gelişmesi ve bununla birlikte zanaatın tarım üretiminden ayrılma sürecinin hızlanması Orta Asya'daki şehir sayısının artmasının ve şehirlerin gelişmesinin başlıca sebebi olmuştur ${ }^{27}$. Şehir bütün zamanlar için her şeyden önce okuryazarlı̆̆ın simgesi olmuştur. Şehirde toplumun en seçkin kısmının yer alması ve şehrin ideoloji, hukuk, yönetim kurulu gibi devlet üst yapısı için lazım olan aydın insanlara olan ihtiyacı şehirde tahsilin gelişmesine yol açmışur.

IX-X. yüzyıllar ve Karahanlı dönemi $\mathrm{O}$ ş ekonomisinin ve kültürünün inkişaf dönemi olduğu anlaşılmaktadır. Bunun en canlı örneği Oş'un yetiştirdiği alimleridir. Ortaçağ İslam müellifleri $O$ ş şehrinde yaşamış, eski Maveraünnehir ilim muhiti ve medeni gelenekleri çevresinde yetişmiş Bağdat, Semerkant, Buhara, Balasagun, Kaşgar vs. gibi İslam dünyasının ilim ve kültür merkezlerinde tahsil, terbiye görmüş ve zamanına göre büyük önem kazanmıs Oş'lu hukukçu, edebiyatçı bilginlerden ve onların eserlerinden söz ederler. Onlardan bazıları şunlardır:

Abu Abdullah Nasırü'd-Din Muhammed b. Süleyman el-Oşi: doğum tarihi hususunda herhangi bir bilgimiz yoktur. İlmini Zahirü'd-Din elMergînânî ve İbrahim b. İsmail el-Saffar'dan almıştır ${ }^{28}$. Kendisi Şemsü'lEimme el-Kerderî ve "el-Hidaye" sahibi Ali el-Mergînânî'nin hocasıdır ${ }^{29}$. ElMergînânî onu "bütün mesmuatı (hocalarından okudukları) hususunda kendi el yazısı ile bize icazet verdi" kaydıyla hocaları arasında zikreder ${ }^{30}$.

Onun vefatından sonra fıkıh Kâdıhan el-Hasan el-Özkendî'nin tabakasına (kuşağına) intikal etmiştir ${ }^{31}$. 592/1195'te vefat eden el-Oşî "Yedi Kadı"nın yanında defn edilmiştir ${ }^{32}$.

El-Oşî, hepsi hukuka ait olan ve hiç birinin bize kadar intikali henüz belli olmayan şu eserleri yazmıştur:

1. Al-Fatava,

2. Sarh Adabi'l-Kazi,

3. Şarh al-Camii'l-Kabir,

${ }^{27}$ Gafurov, B.G., s. $240-241$.

${ }^{28}$ Taşköprüzade, s. 98.

${ }^{29}$ Tasköprüzade, a.y.

${ }^{30}$ Kurașî, 2. c., s. 58.

${ }^{31}$ Taşköprüzade, a.y.

${ }^{32}$ Kuraşî, 2.c., s. 57. 


\section{4. Şarhü'l-Ziyadat.}

Ali b. Osman b. Muhammad El-OŞî: Siracü'd-Din lakabına sahip olmuştur ${ }^{33}$. Fikıh ve edebiyat düzenleri, mahkeme kararları yazarıdır. Hanefi fikıhçlarından olup, 1173'te vefat etmiştir. Eserleri:

1. Savakubü'l-Ahbar,

2. Gurerü'l-Ahbar ve Durerü'l-Eşar fi'l-Hadis,

3. Fatava'l-Siraciya,

4. Kasidatü'l-Amali,

5. Maşarıkü'l-Anvar,

6. Şerh Nisabi'l-Ahbar li Tazkira al-Ahyar fi Muhtasar Gurari'l-Ahbar ${ }^{34}$

Kasidet el-Amâlî'sinde akâidin ana meselelerinden bahseder.

Muhammad b. Ahmad b. Ali b. Halid, Ebi Abdullah el-Oşî: Abu Hafs b. Ali el-Zarancarî'den hadis tahsil etmiştir ${ }^{35}$. Bu hukukçu hac münasebetiyle $611 / 1214$ veya $612 / 1215$ yllında Bağdad'a gelmiş, sonra bu şehirde hadisle uğraşmışur ${ }^{36}$. Bağdad'da bulunduğu sırada başkaları ondan hadis okumuştur ${ }^{37}$ ki, İbn Raynabî onlardan biridir. Sonra Buhara'ya dönen bu alim, oraya yerleşmiş ve orada Hanefi fikhı öğretimiyle meşgul olmuştur ${ }^{38}$. O, $613 / 1216$ 'da Buhara'da vefat etmiș ve Kalabaz'a defnedilmiştir ${ }^{39}$. Onun bize kadar geldiği tesbit edilmeyen Al-Manasik, adlı bir eseri zikredilir ${ }^{40}$.

Mesud b. Mansur el-Oşî kitabı olmayan bir fakihtir. 510/1117 yılında hac münasebetiyle Bağdad'a geldiği zaman Ömer b. Muhammed elZarancarî'den hadis tahsil etmiştir ${ }^{41}$.

Ömer b. Ahmed el-Nesefi "Mesud el-Oşî, çocukları ve ailesi 519/1125 ylında öldüler"der ${ }^{42}$.

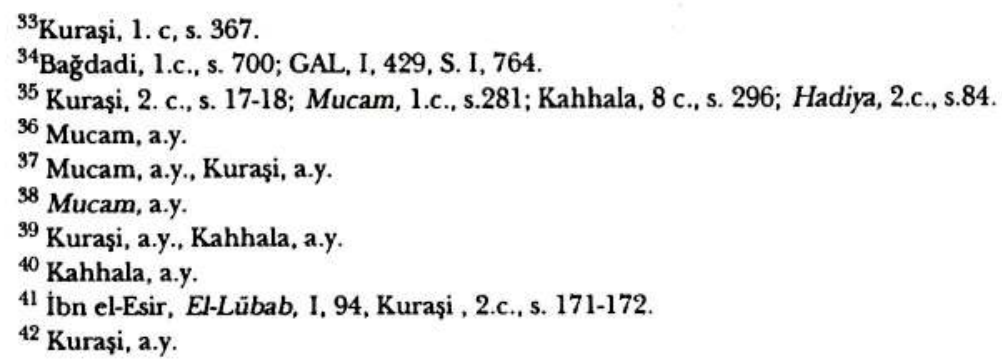


Ömer b. Musa el-Oşi bir fakihtir. İbn el-Esir ile İbn Nukta'nın kitablarında 'İmran b. Mansur el-Oşî" denmektedir ${ }^{43}$. 519/1125'te vefat etmiştii ${ }^{44}$.

Fergana'nın diğer şehirlerinden farklı olarak Oş'ta ortaçağdan kalmıs tarihi eserler çok az muhafaza edilmiştir. Ünlü arkeolog Bernştam'ın sözüyle söylersek "Yeni binalar alunda eski Oş şehri tamamen kayıp olmuştur" 45 Oş şehrinin Süleyman Too dağının (Bara-Kuh) yamacında bulunan ortaçağ mezarlığından "Güristan" kısmı çok iyi derecede muhafaza edilmiştir. Şehrin merkezinde bulunan bu gösterişli dağın eskiden beri ilahileștirildiği bellidir (șehrin kapısının adını hatırlayın). Son dönem kaynaklarda bu dağ ile ilgili Müslüman evliyalarının mezarları hakkındaki bilgiler ilk sıralarda yer almaya başlar. Onlardan Cemalü'd-Din Karşî Mulhakâtu's-Surah adlı eserinde şunları söyler: Oş'ta iki tane küçük dağ vardır. Bunlar Baraka ve Hanaf dağlarıdır. Baraka'nın yanında evliya ve müminlerin mezarları ile Süleyman b. Davud'un veziri Asaf İbn Burhiya'nın mezarı bulunmaktadır ${ }^{46}$. IX-X. yüzyıllarda bu dağın üstünde gözetleme kulesi bulunuyor idiyse de, sonralan burada Karahanlıların ve XIV. yüzyılın ilk yarısı dahil olmak üzere asilzadelerin mezarları yer almaya başlar ${ }^{47}$. $\mathrm{O}$ s şehri ortaçağda çok meşhur olup, bu şöhreti sonraları da devam ettirmiştir ve ona "Hayrü'l-Büldan" (Beldelerin en hayırlısı) adı verilmiştir. Onun iklimi, serveti, güzelliği, kutsallığı hakkında çeşitli rivayetler yerli halk arasında nesilden nesle nakledilmiştir. Bu rivayetlere göre, Taht-1 Süleyman dağında güya Süleyman Peygamberin naaşı bulunuyordu. Ancak, bu tür rivayetler yerli şeyhler tarafindan üretilmiş hadisler ile de destekleniyordu. Onlardan biri: $\mathrm{O} \$$ \$̧ehrinin güya Peygamber Efendimiz tarafindan ziyaret edilmesi ve orada onun taştan yapılmış tahtının kalması gibidir (yani Taht-ı Süleyman).

Hicri 902'de (1496 M.) Timur oğullarından Babür Sultan burada eyvanlı bir hücre (köşk) yaptırmıştur ${ }^{48}$. Bu hücresi (köşkü) hakkında Sultan şunlan söyler: "Kalenin güneydoğusunda Bara-Kuh adlı güzel bir dă̆ vardır. Bu dağın üzerinde Sultan Mahmud Han (amcası- G.A.) bir hücre (köşk) yapturmışt. Onun aşağısında dağın bir çıkıntusında ben de 902'de eyvanlı bir

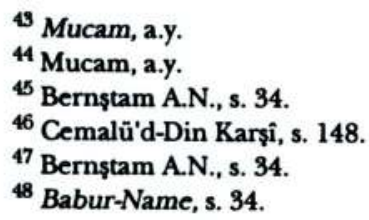


hücre (köşk) yaptırdım. Onun hücresi (köşkü) benimkinden yükseklerde olmasına rağmen benim hücrem (köşküm) daha iyi bir yerde konulmuştur ki, bütün şehir ve civarları onun altundadır." Babür Sultan'ın tasvir ettiği bu hücre (köşk) halk arasında Babür'ün "ak evi" diye anılmıştır, bazen de Hazreti Süleyman Peygamber'in mescidi veya mezarı diye zikredilmiştir. Bu durum zaten halk arasında eskiden beri şehir etrafinda efsanevi bir tarihin ${ }^{49}$ mevcut olmasıyla şehrin ekonomik kudreti, güzelliği, yapıları, evliya ve hanedan mensuplarının mezarları ile birlikte şehrin bölgedeki şöhretini arturmış, ayrıca XX. yüzyılın başına kadar şehri adeta bir mübarek yer ve ziyaret merkezi haline getirmiştir.

\section{BİBLIYOGRAFYA}

1 - Babur-Name, Taşkent, 1993.

2 - El Bagdadî, İsmail Paşa b. Muhammed, Hadiyyatü'l-Arifin Asmaü'lMuellifin va Asarü'l-Musannifin, İstanbul, I, 1951, II, 1955.

3 - Belenitskiy A.M., Bentoviç İ.B., Bolşakov O.G., Srednevekoviy Gorod Sredney Azii, Leningrad, 1973.

4 - Bernştam A.N., Drevnyaya Fergana, Taşkent, 1951.

5 - Besim Atalay, Divanü Lügâti't-Türk Tercümesi, Ankara dört cilt, 1985/1986.

6- Cemalü'd-Din Karşî, Mulhakatü's-Surah // Materialı po İstorii Sredney i Tsentralnoy Azii X-XIX vekov, Taşkent, 1988.

7 - Gafurov B.G., Taciki. Drevneyşaya, Drevnyaya i Srednevekovaya İstoriya, Moskva, 1972.

8 - Galitsky V. Ya., Ploskih V.M., Starinnıy Oş, Frunze, 1987.

9 - Hududü'l-Âlem // Materialı po İstorii Kirgizov $i$ Kigizii, 1.c., Moskva, 1973.

10 - İbnü'l-Fakih el-Hamadanî, Kitabü'l-Büldan, Leiden, 1302.

11 - İbn Havkal, Suratü'-Arz, Beyrouth, 1965.

12 - İbn Hurdadbih, Kitabü'l-Mesalik ve'l-Memalik. Leiden, 1889.

${ }^{49}$ Galitskiy V. Ya, s. 4. 
13 - İstahrî, Abu İshak el-Farisî, Kitabü'l-Mesalik ve'l-Memalik, Leiden, 1927.

14 - Kahhala, Umar Riza, Mucamü'l-Muallifin, Teracim Musannifi'lKutub al-Arabiyya, Dımask, I-XV, 1957-1961.

15- Kuraşi Ebu Muhammed, el-Cevahir el-Muzî'a fi Tabakati'lHanafiyya, I-II. Haydarabad, 1332.

16 - Mukaddesi, Ahsenu't-Tekasim fi Marifeti'l-Ekalim, Leiden, 1906.

17 - Ramazan Şeşen, İslam Coğrafyacılarına göre Türkler ve Türk Ülkeleri, TKAE yayım, Ankara 1985.

18 - Taşköprüzade, Ahmed b. Mustafa, Tabakatü'l-Fukaha, Musul, 1961.

19 - Yakut Hamavi, Mu'camü '-Büldan, Beyrut, I-V, 1955-1957. 